\title{
Avances genómicos de la última década y su influencia en el enfoque diagnóstico de la discapacidad intelectual.
}

\author{
Genomic advances in the last decade and their influence in the diagnosis of intellectual disability.
}

\author{
Hugo Hernán Abarca Barriga 1,2,3,a
}

\section{RESUMEN}

La inteligencia humana es un rasgo poligénico ( $~ 1000$ genes) con una influencia de cada gen aproximadamente ascendente al 0,1\%. Es un atributo indispensable para el desarrollo personal, familiar, social y económico y tiene, además, una relación directamente proporcional al mantenimiento de la salud y a una mayor esperanza de vida. La discapacidad intelectual, consecuentemente, afecta todas estas áreas y constituye un problema de salud pública en varios países de Latinoamérica en los que exhibe una prevalencia mayor al 10\%. La etiología de la discapacidad intelectual sea aislada o sindrómica, es genética hasta en un $85 \%$ de los casos; se diagnostica mediante las nuevas tecnologías de búsqueda en el genoma, tales como la secuenciación masiva y el análisis cromosómico por micromatrices. El diagnóstico etiológico de la discapacidad intelectual permite la selección de terapias específicas, la determinación del pronóstico y de riesgos de recurrencia familiar e individual.

PALABRAS CLAVE: inteligencia, discapacidad intelectual, secuenciación de exoma, análisis de micromatrices, variantes genéticas, variantes en el número de copias.

\section{SUMMARY}

Human intelligence is a polygenic trait $(\sim 1000$ genes), with an approximate influence of $0.1 \%$ per every individual gen. It is an indispensable attribute for personal, familial, social, and economic development; furthermore, it is directly proportional to health maintenance and a longer life expectancy. Consequently, intellectual disability affects all these areas, and constitutes a public health problem in several Latin American countries where it shows a $>10 \%$. In $\sim 85 \%$ of the patients, the etiology of intellectual disability, be that isolated or syndromic; it is mostly diagnosed through the new technological search studies of the genome, such as new generation sequencing and/or chromosomal microarray analysis. The clinical and etiological diagnosis of intellectual disability, when duly confirmed, allows the choice of specific treatment modalities, the precise determination of prognosis, and the estimation of individual or familial recurrence risks.

KEYWORDS: intelligence, intellectual disability, exomic sequencing, chromosomal microarray analysis, genetic variants, copy number variation.

\footnotetext{
Servicio de Genética \& EIM, Instituto Nacional de Salud del Niño-Breña. Lima, Perú.

CP Medicina Humana, Universidad Científica del Sur. Lima, Perú.

Facultad de Medicina Humana, Universidad Ricardo Palma. Lima, Perú.

Médico-Genetista. ORCID: 0000-0002-0276-2557.
} 


\section{Inteligencia}

Inteligencia proviene del latín intelligentia, derivado del verbo intelligěre y compuesta por intus ("entre") y legere ("escoger"). Etimológicamente inteligencia hace referencia a quien "sabe elegir" (1).

La inteligencia está definida como la capacidad para aprender de la experiencia y adaptarse, dar forma y seleccionar entornos (2), o como la capacidad para planificar, aprender "rápido", razonar y resolver problemas $(3,4)$; desempeñando un papel vital en el logro educativo, el éxito profesional y los "desenlaces" positivos o negativos en salud. $(3,5)$ Se mide a través del coeficiente intelectual (CI) mediante diferentes pruebas (ej. StanfordBinet, Wechsler), el cual varía a través de la vida y las generaciones (2). El CI tiene una distribución normal, donde la mayoría de las personas obtienen puntajes que se distribuyen en la parte central, clasificándolo en 7 grupos (gráfico 1) (6-9). Éste CI es variable a través de las diferentes poblaciones existiendo naciones que están alrededor de 70 y otras en 107, los cuales, además, se correlacionan fuertemente con los logros nacionales que se realizan en matemáticas y ciencias (ej.: TIMSS, PISA) $(10,11)$. Según las teorías psicológicas como la teoría $\mathrm{CHC}$, de inteligencias múltiples de Gardner y la triárquica de Stenberg, la inteligencia está basada en subestructuras fundamentales (2).

Se han descrito la relación que existe entre la inteligencia y cambios biológicos como: el volumen cerebral, grosor de la corteza cerebral $\mathrm{y}$ de regiones subcorticales, funcionamiento regional diferenciado, metabolismo de glucosa, neuroplasticidad, neuronas piramidales y el grosor de la sustancia blanca (figura 1) (4). El grosor de la corteza cerebral, específicamente de los lóbulos frontal y temporal se ha correlacionado con la inteligencia. Es así que en los varones existiría una mayor asociación entre las cortezas prefrontal y temporal; mientras que en las mujeres la asociación sería entre las cortezas temporo-occipital (4). En ese mismo sentido, las personas con un coeficiente intelectual alto presentan niveles altos de funcionamiento en la corteza parietal, temporal y occipital, así como en la región subcortical del ganglio striatum, cerebros más voluminosos, mayor tamaño del fascículo uncinado derecho y un metabolismo de la glucosa más bajo durante los procesos de resolución de problemas $(4,12,13)$. La relación entre inteligencia y el volumen de la corteza cerebral va cambiando durante la vida, como producto de una sobreproducción de sinapsis en la niñez y un aumento en la "poda" sináptica en la adolescencia-adultez (4). Además, se reconoce la importancia entre el número de las neuronas piramidales y sus conexiones dendríticas (4).

A pesar del gran avance en la genómica, no existe un gen o genes "claves" para el desempeño normal de la inteligencia. La inteligencia es un rasgo poligénico, donde cada uno de los genes aportan aproximadamente menos del 0,1\% $(2,4)$. Para poder identificar estos genes se ha utilizado la técnica de GWAS (del inglés genome wide association study)

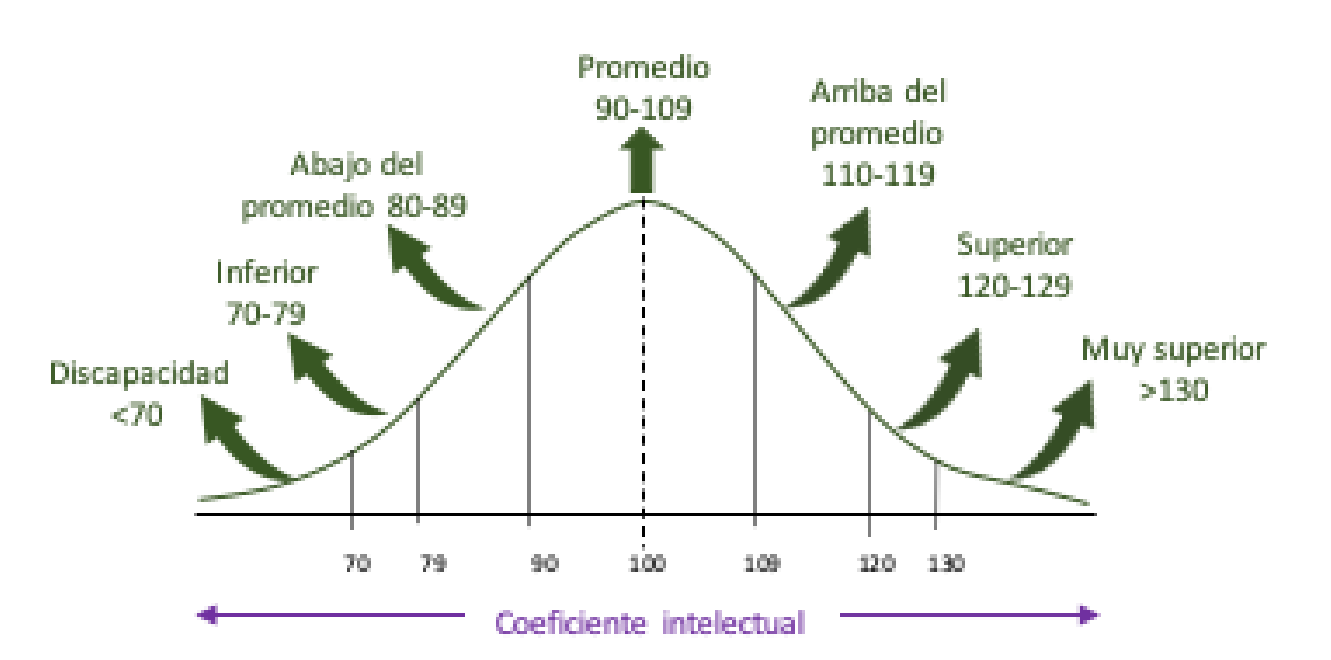

Gráfico 1. Clasificación del coeficiente intelectual. Fuente: Tomado y adaptado de Wechsler (2008). 


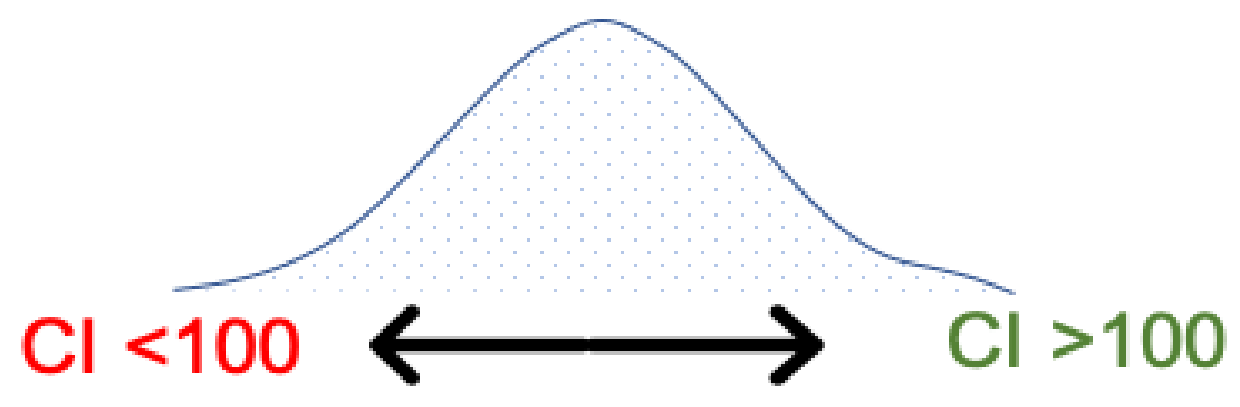

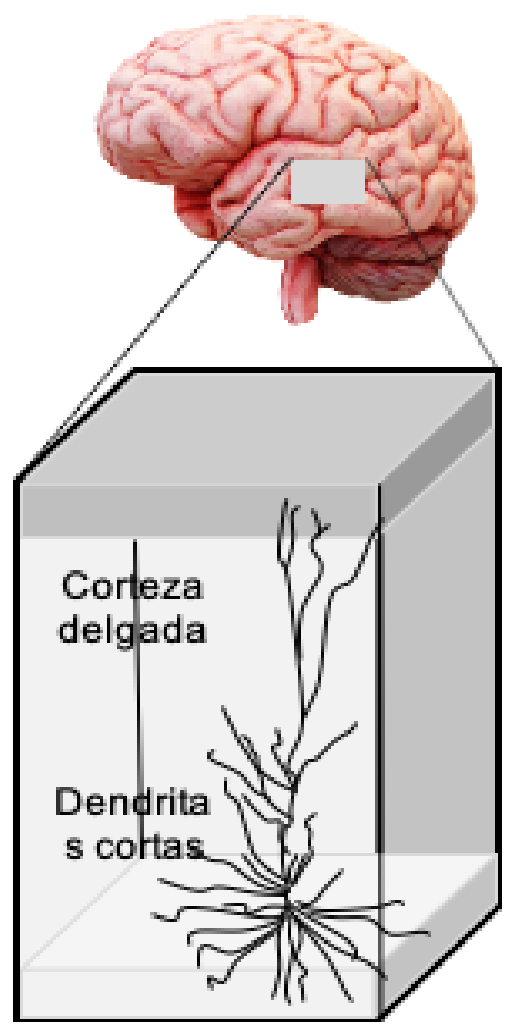

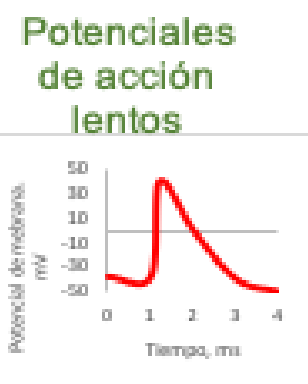

Menos transferencia de

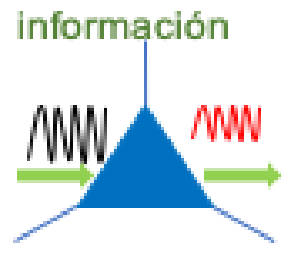

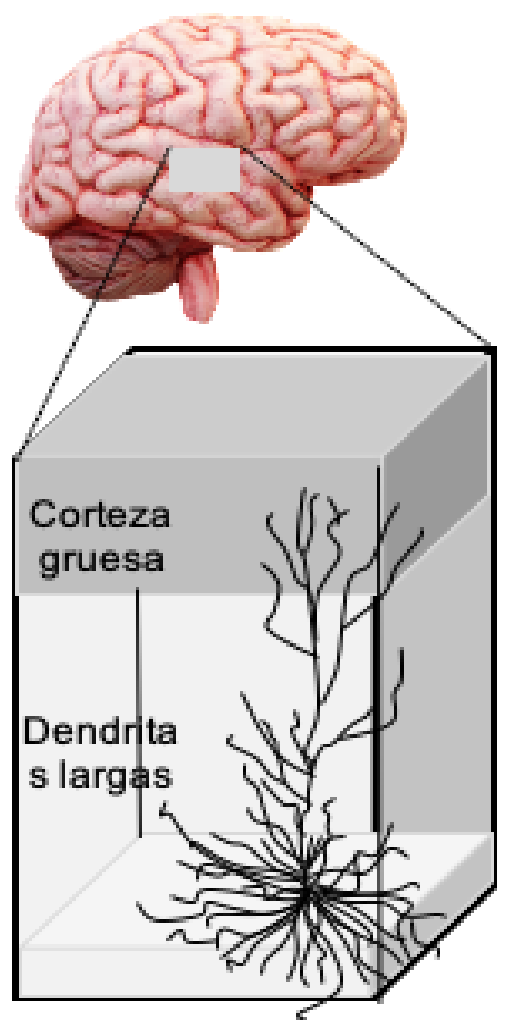

\section{Potenciales} de acción rápidos

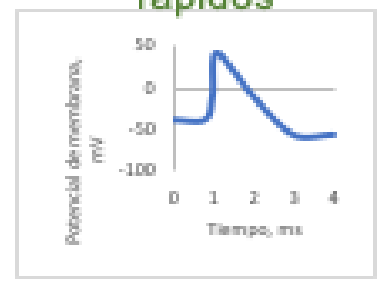

Mayor transferencia de

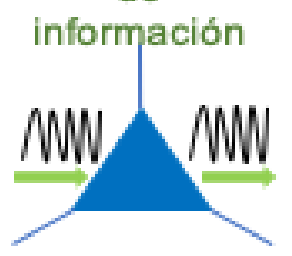

Figura 1. Bases celulares de la inteligencia humana. Un CI alto está relacionado con dendritas más largas, potenciales de acción más rápidos, y una transferencia de información a través de las células piramidales más rápido. Fuente: Extraído y traducido de Gourinova \& Mansvelder (2019).

que utiliza las variantes únicas polimórficas o SNP (del inglés single nucleotide polymorphism)(14). A la fecha, se han llegado a identificar a 1041 genes, los cuales están involucrados en varios procesos como la neurogénesis, regulación del desarrollo del sistema nervioso central (SNC), regulación del desarrollo celular, proyección neuronal, diferenciación del SNC, sinapsis, diferenciación neuronal y de los oligodendrocitos e interacción célula-célula $(4,15)$. Estos SNPs están localizados principalmente en regiones no codificantes, observándose que sólo el $1,4 \%$ de estos SNPs se encuentran en regiones 
exónicas y que la mayoría de estos están activos durante la embriogénesis (ej. DDX27, GNL3, $N C A P G$ ) (4). El cromosoma $\mathrm{X}$ contiene un gran número de genes (aproximadamente unos 120) que intervienen en el aprendizaje y memoria; y además, tiene una mayor densidad de estos genes con relación a los cromosomas autosómicos $(16,17)$.

La heredabilidad se define como la proporción de la variación de los caracteres biológicos de una población, que es atribuible a la variación genotípica entre individuos y mientras más se acerque a uno, la influencia genética es mayor. La heredabilidad de la inteligencia es variable según las etapas del desarrollo encontrándose que podría estar en la niñez en 0,45 y en la adultez entre 0,80 a $0,86(18,19)$, mostrando que, al completar la maduración biológica, la inteligencia está influenciada fuertemente por la genética $(20,21)$. Es más, se ha observado que piezas importantes de la inteligencia se desarrollan en la edad escolar (21). Una de ellas es el control cognitivo que es la capacidad de coordinar pensamientos y acciones para la realización de comportamientos dirigidos a objetivos, sirve como un proceso fundamental en funciones ejecutivas superiores, como el control ejecutivo de la atención, actualización (es decir, memoria de trabajo), desplazamiento e inhibición de la respuesta; este control cognitivo es fundamental en la cognición humana de nivel superior, como la inteligencia (21). Esta capacidad de control cognitivo es altamente hereditaria y está asociado a niveles altos de cognición, y se ha observado que esta heredabilidad varía desde la niñez (6-11 años) hasta la adolescencia (12-18 años) de 0,64 a 0,94 respectivamente $(21)$.

\section{Discapacidad intelectual}

La discapacidad intelectual (DI) o conocida anteriormente como "retraso mental" es uno de los trastornos del neurodesarrollo más frecuentes $(22,23)$, que se caracteriza por la limitación en el funcionamiento intelectual, así como dificultades conceptuales, sociales y áreas prácticas de la vida; que se observan en niños mayores de cinco años (o que pueda realizar la prueba correspondiente) y menores de 18 años $(22,24)$. El diagnóstico de discapacidad intelectual requiere la presencia de los tres criterios siguientes $(22,24)$ :
1. Deficiencia en el funcionamiento intelectual, que incluye razonamiento, resolución de problemas, planeamiento, pensamiento abstracto, juicio, aprendizaje académico, aprendizaje desde la experiencia; el cual ha sido confirmado clínicamente de manera individualizada con pruebas estandarizadas de CI.

2. Déficit en el funcionamiento adaptativo que obstaculiza significativamente la conformidad con los estándares de desarrollo y socioculturales para la independencia y la capacidad del individuo de cumplir con su responsabilidad social.

3. La edad de inicio de estas deficiencias es durante la niñez.

La clasificación de la severidad de la discapacidad intelectual es en cuatro grupos (tabla 1) (22).

La prevalencia mundial de la discapacidad intelectual (DI) oscila entre 1 y el 3\% de la población y el $90 \%$ tiene una etiología genética (25). Según la gravedad, la prevalencia variará (tabla 1) y la relación varón: mujer es de 2:1 $(26,27)$. En Latinoamérica la prevalencia de DI varía entre el $3 \%$ al $12,9 \%$ de la población (28), sin embargo, estos valores podrían ser más altos llegando al 18,3\% en países de bajos o medianos ingresos (29-31). En el Perú no se tiene registro sobre la prevalencia de DI, sin embargo, se estima que entre 0,9 y 5 millones de peruanos tendrían DI.

La DI tiene un impacto social y económico muy alto en la salud pública; es así, que los costos durante la vida de un paciente con DI (en EE. UU. y Europa) está entre 1-2 millones de dólares, siendo más costoso que la demencia y el cáncer (31).

\section{Etiología de la discapacidad intelectual}

La DI, así como el retraso del desarrollo psicomotor (RDPM) y el trastorno del espectro autista (TEA) son síntomas y signos que no expresan la etiología subyacente (32). El RDPM se define como el retraso en niños menores de cinco años en dos o más de las siguientes áreas: i) motora (gruesa y fina), ii) habla y lenguaje (expresivo y receptivo) iii) social y emocional y iv) cognitivo (23). Y el TEA describe un comportamiento caracterizado por incapacidad en la interacción social, restricción 
Avances genómicos de la última década y su influencia en el enfoque diagnóstico de la discapacidad intelectual.

de intereses y comportamientos repetitivos, cuyo diagnóstico se realiza a través de pruebas neuropsicológicas especializadas (33-35). Estos tres trastornos del neurodesarrollo tienen que ser diferenciados y la DI se puede o no manifestar en la infancia como un retraso del desarrollo psicomotor, y pueden o no asociarse a TEA. Por lo tanto, todo paciente que presente alguna de estas características se deberá buscar la etiología.

La DI se clasifica en sindrómica si está asociada a una patología específica (ej. anomalías congénitas, talla baja, obesidad, epilepsia) y en no sindrómica o aislada (36).

La etiología de la DI es muy heterogénea, es así como una forma práctica de clasificarlas es de la siguiente manera: i) genéticas ii) teratogénicas iii) otras (figura 2) (32).

\section{Etiología genética}

La discapacidad intelectual tiene un origen genético hasta en un $90 \%$ de los casos estudiados, utilizando toda la tecnología disponible hasta el momento $(25,37,38)$.

Las enfermedades genéticas que presentan DI aislada o sindrómica son causadas por variantes de un único nucleótido o $S N V$ (del inglés single nucleotide variation), de múltiples nucleótidos o $M N V$ (del inglés multinucleotide variation) o las variantes en el número de copias o $\mathrm{CNV}$ (del inglés copy number variation) (39). Estas variantes genéticas pueden ser determinantes para modificar la inteligencia, la cual dependerá de su función, la frecuencia de aparición con relación a la población y su interrelación con el medio ambiente (figura 2) (36).

En pacientes con DI no sindrómica, se ha descrito que existe una alteración en la neurotransmisión

Tabla 1. Clasificación de la severidad de la discapacidad intelectual.

\begin{tabular}{|c|c|c|c|c|c|c|}
\hline $\begin{array}{l}\text { Categoría } \\
\text { de la } \\
\text { severidad }\end{array}$ & $\begin{array}{l}\text { Distribución } \\
\text { aproximada } \\
\text { del } \\
\text { porcentaje } \\
\text { según } \\
\text { severidad }\end{array}$ & $\begin{array}{l}\text { Prevalencia en } \\
\text { la población }\end{array}$ & $\begin{array}{l}\text { Criterio } \\
\text { según } \\
\text { DSM-IV } \\
\text { (Basado } \\
\text { sólo en CI) }\end{array}$ & $\begin{array}{l}\text { Criterio según DSM- } \\
5 \text { (clasificación de la } \\
\text { severidad en base } \\
\text { a las habilidades } \\
\text { diarias ) }\end{array}$ & $\begin{array}{l}\text { Criterios } \\
\text { según AAIDD } \\
\text { (clasificación de la } \\
\text { severidad basado } \\
\text { en las necesidad } \\
\text { de soporte) }\end{array}$ & $\begin{array}{l}\text { Criterio según } \\
\text { SSI ( la lista de } \\
\text { SSI no especifica } \\
\text { la severidad, pero } \\
\text { indica los estándares } \\
\text { diferentes para reunir } \\
\text { o equiparar el listado } \\
\text { de la severidad) }\end{array}$ \\
\hline Leve & $85 \%$ & $4-12 \%$ & $50-69$ & $\begin{array}{l}\text { Puede vivir } \\
\text { independientemente } \\
\text { con un niveles } \\
\text { mínimos de soporte }\end{array}$ & $\begin{array}{l}\text { Se necesita apoyo } \\
\text { intermitente } \\
\text { durante las } \\
\text { transiciones } \\
\text { o períodos de } \\
\text { incertidumbre. }\end{array}$ & $\begin{array}{l}\text { CI de } 60 \text { a } 70 \text { y un } \\
\text { impedimento físico o } \\
\text { mental que impone una } \\
\text { limitación adicional } \\
\text { y significativa de la } \\
\text { función }\end{array}$ \\
\hline Moderada & $10 \%$ & $2-2,5 \%$ & $36-49$ & $\begin{array}{l}\text { La vida independiente } \\
\text { se puede lograr con } \\
\text { niveles moderados } \\
\text { de apoyo, como } \\
\text { los disponibles en } \\
\text { hogares grupales }\end{array}$ & $\begin{array}{l}\text { Apoyo limitado } \\
\text { necesario en } \\
\text { situaciones diarias }\end{array}$ & $\begin{array}{l}\text { Un cociente intelectual } \\
\text { verbal, de rendimiento } \\
\text { o a gran escala válido } \\
\text { de } 59 \text { o menos }\end{array}$ \\
\hline Severa & $3,5 \%$ & $0,5 \%$ & $20-35$ & $\begin{array}{l}\text { Requiere diariamente } \\
\text { asistencia con } \\
\text { actividades de } \\
\text { autocuidado y } \\
\text { supervisión de } \\
\text { seguridad }\end{array}$ & $\begin{array}{l}\text { Apoyo amplio } \\
\text { necesario para las } \\
\text { actividades diarias. }\end{array}$ & $\begin{array}{l}\text { Un cociente intelectual } \\
\text { verbal, de rendimiento } \\
\text { o a gran escala válido } \\
\text { de } 59 \text { o menos }\end{array}$ \\
\hline Profunda & $1,5 \%$ & & $<20$ & $\begin{array}{l}\text { Requiere } 24 \text { horas de } \\
\text { cuidado }\end{array}$ & $\begin{array}{l}\text { Se necesita apoyo } \\
\text { generalizado para } \\
\text { todos los aspectos } \\
\text { de las rutinas } \\
\text { diarias }\end{array}$ & $\begin{array}{l}\text { Un cociente intelectual } \\
\text { verbal, de rendimiento } \\
\text { o a gran escala válido } \\
\text { de } 59 \text { o menos }\end{array}$ \\
\hline
\end{tabular}




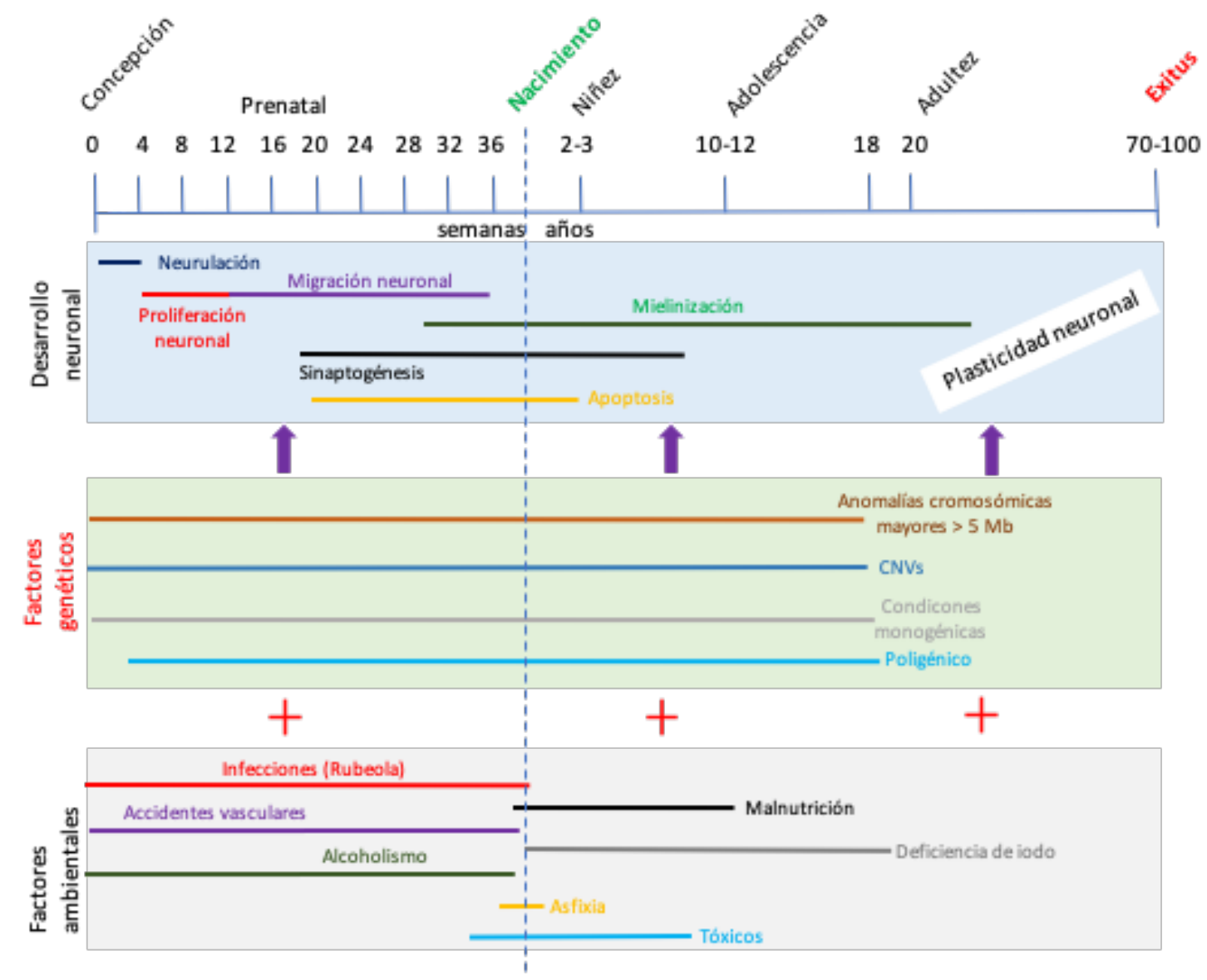

Figura 2. Etiología de la discapacidad intelectual. Los trastornos genéticos y ambientales pueden influir negativamente en el desarrollo neuronal. Estas variantes genéticas y ambientales actúan en conjunto para provocar un determinado fenotipo, el cual se puede observar, a través de otras comorbilidades, desde la etapa prenatal (ej. Malformaciones), neonatal (ej. Hipotonía, epilepsia), niñez (ej. Retraso del desarrollo psicomotor, TEA) o en la etapa adulta (ej. Esquizofrenia). Fuente: Extraído, traducido y modificado de Le Hellard \& Steen (2014).

glutamatérgica y dopaminérgica (40). Estas alteraciones excitatorias-inhibitorias no sólo ocurren en el cerebro, sino también en el conectoma cerebelar (cerebelo-núcleo-tálamo) (41).

\section{Enfermedades monogénicas}

Provocado por variantes en un solo gen y pueden ser SNV, MNV o CNV (39).

En OMIM (del inglés online mendelian inheritance in man) existen más de 708 entidades que presentan discapacidad intelectual (ver: www. omim.org). Sin embargo, aún existen entidades que a la fecha no han sido catalogadas en OMIM (gráfico 2); describiéndose a más de 1000 loci asociados a discapacidad intelectual (42), y que el número de genes implicados serían más de 2065 genes, según el portal de SysID (http://sysid.cmbi.umcn.nl/) $(43,44)$. Los tipos de herencia son enfermedades dominantes autosómicas (ej. síndrome Sotos), dominante ligado al cromosoma X (ej. síndrome del X frágil), recesivas autosómicas (ej. errores innatos del metabolismo), recesivas ligadas al cromosoma $\mathrm{X}$ (ej. síndrome de deficiencia de creatina 1) o mitocondriales.

Existe un mayor número de genes que están relacionados a la herencia recesiva autosómica, en comparación a los otros tipos (gráfico 3). Se ha reportado, que el número de genes que con certeza provocan DI de herencia recesiva autosómica estaría entre 1 222- $2000(44,45)$, y los genes candidatos adicionales serían de 1127 (44).

En las entidades de herencia dominante, éstas pueden ser por variantes de novo, heredadas de uno 
Avances genómicos de la última década y su influencia en el enfoque diagnóstico de la discapacidad intelectual.

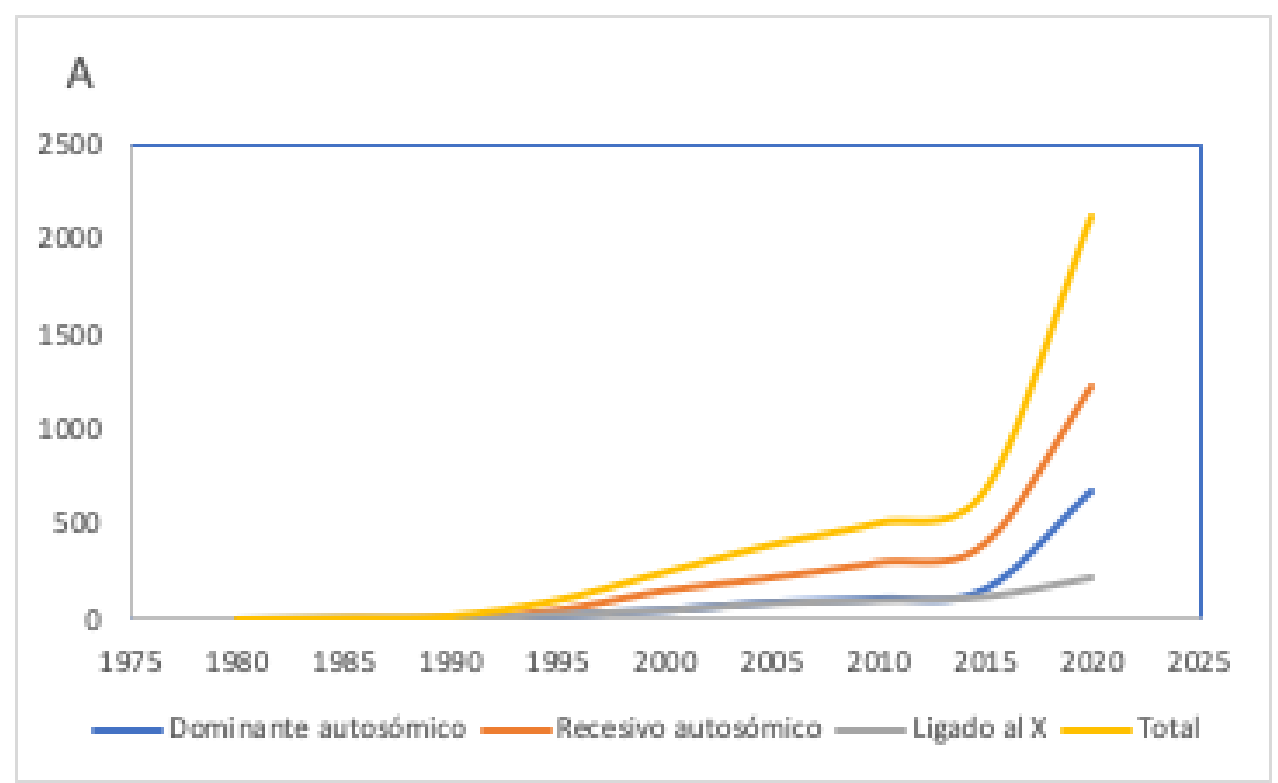

Gráfico 2. Número de genes descritos anualmente que están ligados a DI aislada y DI sindrómicas, observándose un crecimiento exponencial en estos últimos años. Fuente: Extraído, traducido y modificado de Vissers et al. 2017

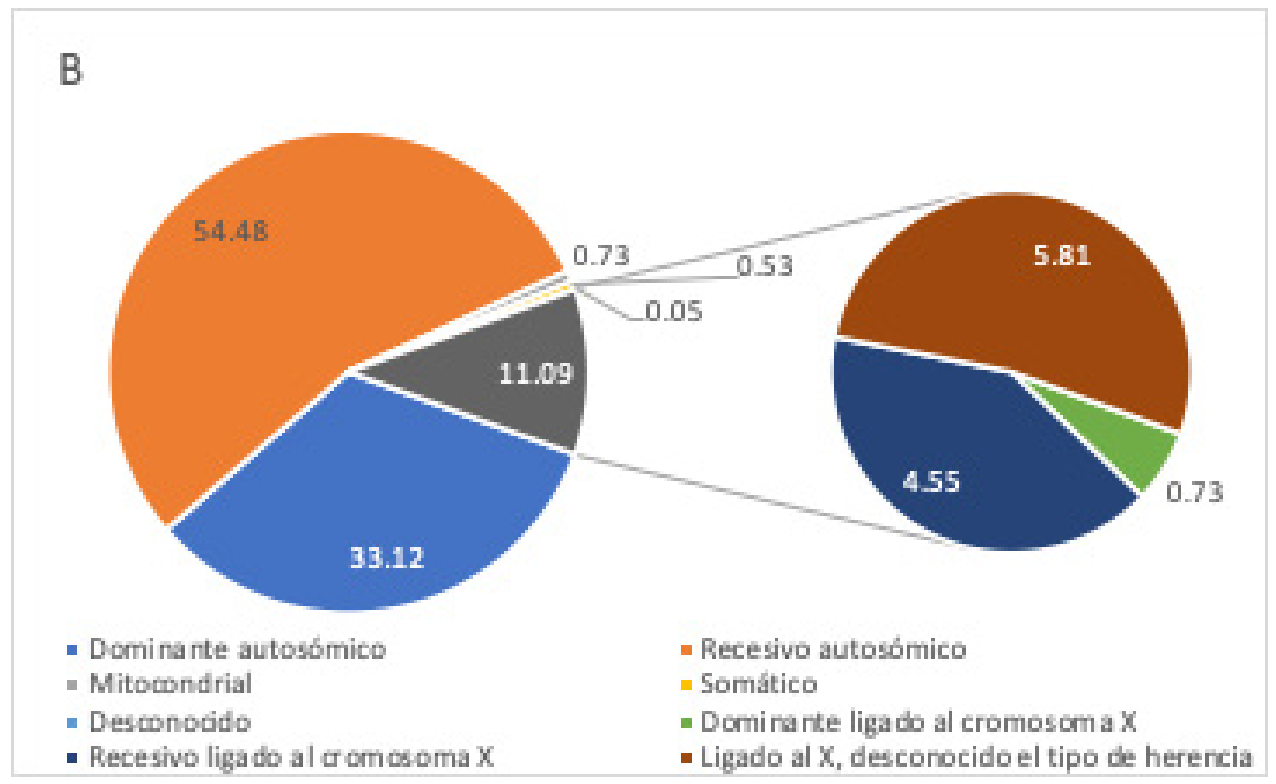

Gráfico 3. Proporción de genes según el tipo y patrón de herencia. Existen más genes de herencia recesiva autosómica. Fuente: Elaboración propia, datos extraídos de http://sysid.cmbi.umcn.nl/.

de los padres o mosaicismos gonadales (46). Lo que se conoce es que un neonato presenta 50-100 variantes de novo a nivel diploide (ej. 38 variantes por sustitución, 3 pequeñas inserciones-deleciones $\mathrm{y}$ una variante en splicing), resultando en 0,86 variantes que modifican un aminoácido $(42,47)$.

Como se mencionó la discapacidad intelectual es más frecuente en varones que en mujeres (2:1).
Esta diferencia se debe a la presencia de un segundo cromosoma $\mathrm{X}$ en la mujer y a la cantidad y densidad de genes relacionados con la inteligencia que contiene este cromosoma $(16,17)$.

\section{Alteraciones cromosómicas}

En los pacientes que tienen DI profunda, se puede observar anomalías cromosómicas microscópicas 
en el $12-35 \%$ de los casos, en DI moderada-severa $\sim 3 \%$, y en los casos leves entre el $1-3 \%$ (promedio del 4,6\%) (26,31).

Dentro de las alteraciones numéricas o aneuploidías, se tiene como ejemplo al síndrome Down, con una frecuencia de $3,45 / 700$ recién nacidos vivos (48), y corresponde al $12 \%-36 \%$ de los casos con DI $(31,49)$, donde la fisiopatología de la DI es por triplosensibilidad o sobrexpresión en varios genes (ej. DYRK1A, RCAN1, RIP140, CSB, miR155, $S O D 1, A P P)$ que están involucrados en procesos del neurodesarrollo (ej. neurogénesis, plasticidad sináptica, neurotransmisión) o aumento en la neurodegeneración (ej. estrés oxidativo, patología amiloide o muerte celular neuronal)(50).

Las variantes en el número de copias o CNV (del inglés copy number variation) o conocidas anteriormente como microdeleciones microduplicaciones, son segmentos de ADN mayor a $1 \mathrm{~kb}$ (51). Las CNVs más frecuentes tienen una prevalencia entre 1/1 000 a 1/25 000 (52); y los fetos tienen una incidencia de $0,7 \%(53)$. En los pacientes con DI se pueden encontrar como causa de la DI en el 20-25,8\% de los pacientes (54). Dependiendo de si existiera una CNV en ganancia o pérdida provocará triplosensibilidad o haploinsuficiencia respectivamente. Otra manera de provocar un fenotipo es por la fusión de genes o disrupción de estos. Se ha encontrado que algunas $\mathrm{CNV}$ s que no contienen genes (CNVs no codificantes), son regiones reguladoras de otro(s) gen(es) $(39,55,56,57)$. Las alteraciones subteloméricas (un tipo de CNVs), provocan entre el $5-7 \%$ de los pacientes (58). Otras CNVs frecuentes son por ejemplo el síndrome Prader-Willi/Angelman, síndrome Williams, síndrome de deleción 22q11.2 (31).

\section{Etiología teratogénica}

Existen diversos teratógenos que tienen efectos adversos en el desarrollo del sistema nervioso central (59). El mecanismo de sus efectos es muy complejo y depende de diversos factores como del grado y tiempo de exposición, de la susceptibilidad genética de la madre y el feto, del tipo de teratógeno, entre otros. Se ha demostrado que la exposición aguda o crónica a factores ambientales como el abuso de drogas o sustancias tóxicas durante períodos críticos del desarrollo causa alteraciones globales o específicas de genes a través de modificaciones de histonas, remodelación de cromatina o metilación de ADN en diferentes áreas del cerebro (60).

Entre estos factores ambientales que actúan como teratógenos en el desarrollo cerebral tenemos al alcohol, observándose que el consumo aún en cantidades mínimas, tienen un riesgo de tener hijos con trastorno del espectro alcohol fetal, provocando cambios epigenéticos que modularían la expresión y función génica, y que además podría influir en generaciones posteriores.(61-64) Específicamente, se postula que durante la exposición al alcohol en la etapa embrionaria-fetal el mir-9 disminuye, quien está relacionado en la segmentación cerebral, neurogénesis y maduración neuronal (65). Otros teratógenos, relativamente frecuentes, se tiene a la isotretinoina $(66,67)$ (induce la expresión anómala de genes implicados en la diferenciación neuronal) (68), al misoprostol $(69,70)$, la deficiencia de ácido fólico (71) y la infección por rubeola $(72,73)$.

\section{Factores de riesgo}

Los factores de riesgo de este trastorno del neurodesarrollo son consanguinidad, la edad materna mayor a 35 años, educación materna menor a 12 años, pretérmino $(<37$ semanas), sexo masculino, bajo peso al nacer $(<2500)$, paridad $(>=3)$, alcoholismo, tabaquismo y epilepsia y asma materno $(74,75)$.

El riesgo de aparición de variantes en el número de copias de novo está relacionado a madres mayores de 35 años (76). Sin embargo, es importante precisar que la edad paterna mayor a 29,7 años es un factor de riesgo para la aparición de variantes de novo (sean SNV, MNV o CNV) asociados a trastornos del neurodesarrollo, incluida la DI (77).

\section{Prevención de la discapacidad intelectual}

Están incluidas medidas como el tamizaje neonatal universal para condiciones potencialmente tratables (ej. hipotiroidismo congénito, fenilcetonuria), vacunación contra rubeola, administración de ácido fólico, mejoras en el cuidado del embarazo, evitar el consumo de alcohol $(78,79)$. Específicamente los errores innatos del metabolismo tienen tratamiento refinados, de ahí la importancia de su diagnóstico 
oportuno a través del tamizaje neonatal universal (29). Además, es importante el disminuir las uniones matrimoniales consanguineas.

\section{Comorbilidades}

La discapacidad intelectual puede acompañarse en el $30-57 \%$ con otros trastornos del neurodesarrollo, como encefalopatía epiléptica, TEA, esquizofrenia, parálisis cerebral, ceguera e hipoacusia $(22,43,80)$. Otras comorbilidades son trastorno bipolar, trastorno de hiperactividad y déficit de atención (59).

\section{Diagnóstico etiológico de la discapacidad intelectual.}

El diagnóstico de DI nos permite: i) conocer la etiología, ii) pronóstico o conocer el curso clínico, iii) informar a la familia sobre los mecanismo(s) genético(s) y el riesgos de recurrencia familiar, iv) optar tratamientos refinados, v) racionalizar las pruebas de diagnóstico, vi) proveer información relativa al tratamiento, los síntomas, gestión o vigilancia de complicaciones, vii) prestación de apoyo a la familia según la condición específica, viii) acceso a los protocolos de tratamiento de investigación, y ix) garantizar una mejor salud, así como una atención sociosanitaria, donde exista una satisfacción de los servicios, interpretados de una manera adecuada según los resultados (niño y su familia) (81).

El diagnóstico clínico de la etiología de la discapacidad intelectual se realiza utilizando la siguiente estructura (figura 3 ):

i. Antecedentes prenatales, natales y del desarrollo psicomotor.

ii El pedigrí de tres generaciones, el cual ayuda a precisar consanguinidad, antecedentes familiares con patología similar o psiquiátrica (ej. psicosis, depresión, TEA) (32).

iii El examen físico incluyendo una antropometría detallada, evaluación de dismorfias, uso de lámpara de Wood y el registro fotográfico (con la finalidad de realizar comparaciones con casos similares anteriores o compartir la información con otros especialistas) $(32,82,83)$.

Se ha determinado que los datos de la anamnesis general, antecedentes prenatales, perinatales, familiares y una exploración dismorfológica adecuada orientan certeramente el diagnóstico entre el 39\% y
$81 \%$ de los casos $(82,83)$. La exploración neurológica contribuye hasta en el $42 \%$ al diagnóstico sindrómico $(82,83)$. El uso de motores informático de búsqueda de síndromes específicos síntomas o dismorfias faciales específicas como OMIM (www.omim.org), Face2gene/LMD (London Medical Databases), Possum, Phenomizer, Findzebra; contribuyen en el diagnóstico diferencial (84-92).

Si existe una sospecha clínica alta debido a que el paciente presenta características "patognomónicas" de alguna enfermedad genética, es siempre mejor realizar la prueba genética que dará la confirmación; el cual podrá ser cariotipo, test de metilación, análisis cromosómico por micromatrices, o secuenciación. Por ejemplo, en pacientes con distonía y/o epilepsia se puede determinar las variantes en el gen $A R X$ (93). En cualquier varón con hipotonía congénita y un retraso del desarrollo psicomotor severo se deberá examinar la presencia de variantes del gen MECP2 (94). Entre el 0,2-3,5\% de los varones con DI, se ha observado variantes del SLC6A8, el cual provoca el síndrome de deficiencia de creatina cerebral (95). En ese mismo sentido, si existiera la sospecha de alguna CNV específica (ej. síndrome Williams, síndrome de deleción 22q11, síndrome Prader-Willi), se puede realizar FISH (del ingles fluoroscence in situ hibridization) o MLPA (del inglés múltiple ligation probe amplification) (96). Las pruebas genéticas son complementarias entre sí, ya que a la fecha no se ha identificado una prueba que pueda detectar de manera simultánea todas las variantes genéticas, llámese SNV, MNV o CNV.

El cariotipo (mayor a 650 bandas) detecta la etiología sólo en el 3\% de los pacientes con DI sin un diagnóstico clínico específico (82). Debido a que las variantes en el número de copias mayores a 3-5 $\mathrm{Mb}$, es detectada si la resolución es de 1000 bandas, y CNVs de $10 \mathrm{Mb}$ si la resolución es de $\sim 400-500$ bandas (97).

En aquellos pacientes sin un diagnóstico clínico, se procederá en realizar exámenes que evalué todo el genoma. Así, comenzaremos con la secuenciación de exoma/genoma; luego se utilizará el análisis cromosómico por micromatrices o CMA (del inglés chromosomal microarray analysis).

La secuenciación masiva, específicamente la secuenciación de exoma tiene una tasa de detección 
Evaluación Clínica-Genética

1.Historia Clínica.

2.Historia Familiar(tres generaciones).

3.Examen físico

4.Examen dismorfológico

5.Examen neurológico

6.Fotografía.

7. Evaluación oftalmológica y audiológica

8.Citogenética molecular y clásica.

9.Estudios moleculares: secuenciación de

exoma, FISH subtelómeros, MLPA, SLC26A,

ARX, FMR1,

10.Estudio de EIM

11.Imágenes: $\mathrm{RMN}, \mathrm{TAC}, \mathrm{Rx}$, ecografía.

\section{Historia clínica}

Historia familiar

Examen físico

Examen dismorfológico

Examen neurológico

\section{Secuenciación de exoma}

2. CMA (750K)

$\mathrm{y}$

Determinación de CGG de FMR1

Si es negativo:

Estudios metabólicos de EIM

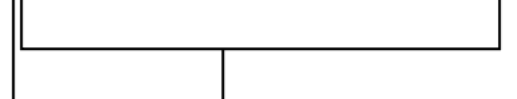

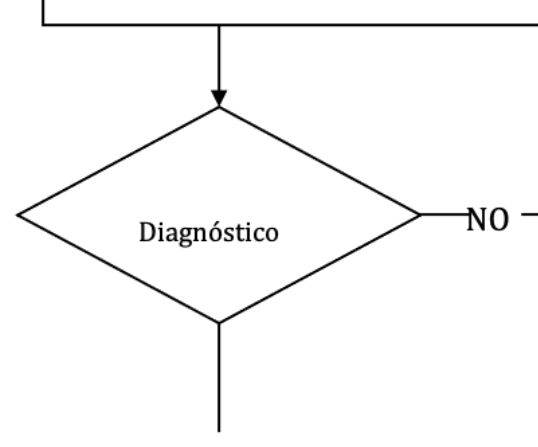

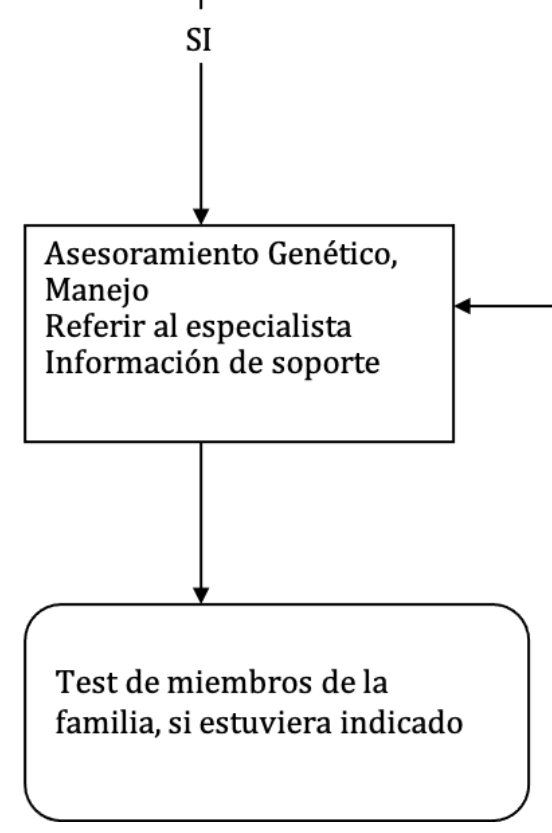

\section{Secuenciación genómica}
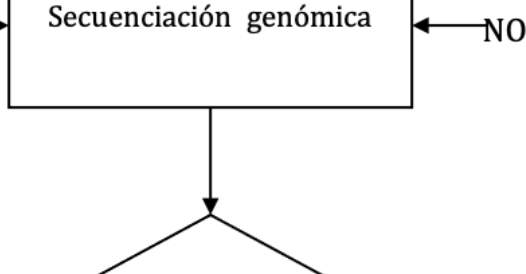

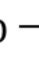

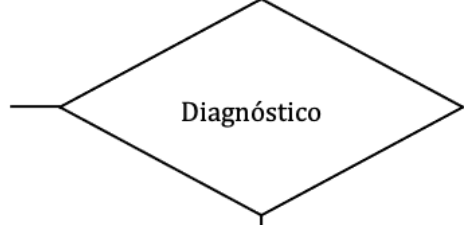

Confirmación con los siguientes pruebas:

Citogenética, FISH

subtelómeros, MLPA

FMR1, estudio de EIM,

secuenciación, CMA

Figura 3. Algoritmo diagnóstico de la discapacidad intelectual. EIM= Errores innatos del metabolismo, CMA= Análisis cromosómico por micromatrices, MLPA= Multiple ligation probe amplification. Fuente: Elaboración propia. 
superior al CMA (98) y que está alrededor del $31 \%$ y $53 \%$ en pacientes con DI aislado y sindrómico, respectivamente (promedio del 36\%) (99), por lo que actualmente debería ser la primera prueba de elección para determinar la etiología de la DI (100).

El CMA sirve para determinar CNVs (deleciones o duplicaciones submicroscópicas) el cual en algunos centros sigue siendo el primer test de elección en niños con DI. $(101,102)$ El uso de CMA en pacientes con DI detecta la etiología entre el $15-25,8 \%$ de los casos (101-103); sin embargo, si sólo se realiza CMA a los pacientes con DI y dismorfia facial el rango puede llegar entre el 33-40\% (104-106). Además, las que utilizan marcadores SNP tienen la ventaja adicional de poder determinar regiones de homocigosidad o $\mathrm{ROH}$ (del inglés región of homozigosity) el cual si estuviera alterada indicaría posibles disomías uniparentales o incluso indicarnos coeficiente de endogamia altos, lo cual estaría en relación con una posible entidad de herencia recesiva autosómica (75). Las disomías uniparentales, según la región afectada, estaría relacionada a genes en los que se ha modificado la impronta o la aparición de enfermedades recesivas autosómicas (107).

Es importante precisar que todo paciente con RDPM/DI, y en especial en aquellos sin compromiso motor, debería verificarse la expansión de tripletes CGG del gen FMRl (síndrome del X frágil). El síndrome del $\mathrm{X}$ frágil se observa en el 2-3\% de los varones y en el $1-2 \%$ de las mujeres con DI (83), siendo así la segunda causa más frecuente de DI, después del síndrome Down (108).

Las pruebas para determinar errores innatos del metabolismo son múltiples y nos pueden ayudar en el diagnóstico en un $0-8,4 \%$ de los pacientes con DI,

Tabla 2. Estudios metabólicos especializados utilizando tecnología metabolómica, para la búsqueda de algunos EIM.

\begin{tabular}{|c|c|c|c|c|}
\hline Enfermedades & Estudios metabólicos & Muestra & Tecnología utilizada & Referencias \\
\hline Trastorno de ácidos orgánicos & $\begin{array}{l}\text { Ácidos orgánicos cuali y } \\
\text { cuantitativos }\end{array}$ & Orina & $\begin{array}{l}\text { Cromatografía de } \\
\text { gases acoplada a } \\
\text { espectrometría de } \\
\text { masas }\end{array}$ & Ramsay et al. 2018 \\
\hline $\begin{array}{l}\text { Trastornos de aminoácidos } \\
\text { aromáticos, de cadena ramificada } \\
\text { y azufrados, ciclo de la úrea, } \\
\text { transporte de aminoácidos y de la } \\
\text { glicina }\end{array}$ & $\begin{array}{l}\text { Cuantificación de } \\
\text { aminoácidos }\end{array}$ & Plasma & $\begin{array}{l}\text { Cromatografía de } \\
\text { intercambio iónico }\end{array}$ & Sandlers 2019 \\
\hline Mucopolisacaridosis & $\begin{array}{l}\text { Cuantificación de } \\
\text { glicosaminoglicanos }\end{array}$ & Orina & $\begin{array}{l}\text { Cromatografía } \\
\text { líquida acoplada a } \\
\text { espectrometría de } \\
\text { masas }\end{array}$ & Stapleton et al. 2020 \\
\hline $\begin{array}{l}\text { Alfa-manosidosis y } \\
\text { aspartilglucosaminuria, trastornos } \\
\text { del metabolismo de glicanos }\end{array}$ & Oligosacáridos & Orina & $\begin{array}{l}\text { Espectrometría de } \\
\text { masas en tándem }\end{array}$ & Davids et al. 2018 \\
\hline $\begin{array}{l}\text { Trastorno de la oxidación } \\
\text { mitocondrial de ácidos grasos y de } \\
\text { aminoácidos de cadena ramificada }\end{array}$ & Perfil de acilcarnitina & Plasma & $\begin{array}{l}\text { Espectrometría de } \\
\text { masas en tándem }\end{array}$ & $\begin{array}{l}\text { Millington and Steven. } \\
2011\end{array}$ \\
\hline $\begin{array}{l}\text { Homocistinuria, deficiencia de } \\
\text { cobalamina C, D, E, F y G, y } \\
\text { deficiencia de MTHFR }\end{array}$ & Homocisteina & Plasma & Inmunoensayo & van Karnebeek et al. \\
\hline $\begin{array}{l}\text { Deficiencia del cofactor de } \\
\text { molibdeno tipo A, Superactividad } \\
\text { de la pirimidina 5-nucleotidasa }\end{array}$ & Purina/pirimidinas & Orina & $\begin{array}{l}\text { Cromatografía } \\
\text { líquida acoplada a } \\
\text { espectrometría de } \\
\text { masas }\end{array}$ & van Karnebeek et al. \\
\hline $\begin{array}{l}\text { Deficiencia de arginina:glicina } \\
\text { amidinotransferasa, deficiencia } \\
\text { guanidinoacetato metiltransferasa } \\
\text { y transportador de creatina }\end{array}$ & Metabolitos de creatina & Orina & $\begin{array}{l}\text { Cromatografía } \\
\text { líquida acoplada a } \\
\text { espectrometría de } \\
\text { masas }\end{array}$ & van Karnebeek et al. \\
\hline
\end{tabular}




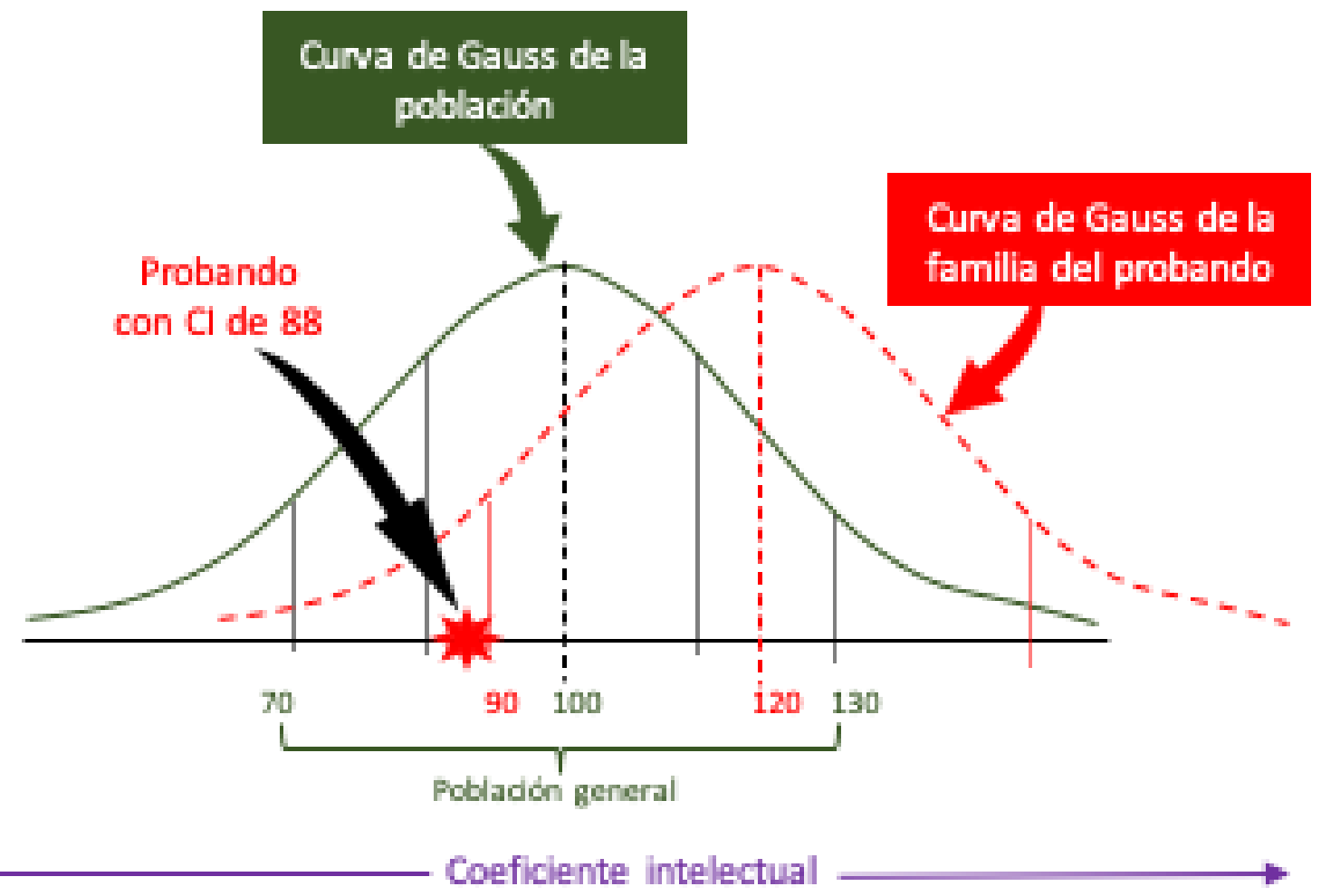

Gráfico 4. Medición del CI familiar (en el ideal padres, hermanos, tíos) con la finalidad de estimar la curva normal familiar, en pacientes con bajo rendimiento escolar y CI $>70$. Si la curva estimada "familiar" del CI estuviera por encima, sería necesario utilizar el protocolo de atención de pacientes con DI. En el ejemplo, se observa que el probando tiene un CI de 88; no obstante, a pesar de estar dentro de las curvas normales, está por debajo del estimado familiar. Fuente: Elaboración propia, los puntos de corte de la población general son extraídos de Wechsler (2008).

con un promedio del 1\% $(106,109)$. Estos exámenes son generales (ej. lactato, gases venosos, electrolitos, perfiles hepático y tiroideo, cetonas, amonio, magnesio, ceruloplasmina, cobre, hierro, CPK) y los especializados (tabla 2) $(27,106,110)$. La ventaja de búsqueda de este grupo de patologías es que existen al menos 81 entidades que tienen una terapéutica específica (http://www.treatable-id.org)(80,111,112) por lo tanto el cribado neonatal universal mediante políticas públicas es de suma importancia, con la finalidad de diagnosticar oportunamente y mejorar a largo plazo los objetivos del tratamiento (27).

Otros exámenes auxiliares como la TEM, y la resonancia magnética $(\mathrm{RMN})$ que permiten establecer las alteraciones estructurales del desarrollo cerebral ayudan en el diagnóstico etiológico entre el 0\%-3,9\%, siendo más sensible el uso de la RMN (109). En este mismo sentido, el uso del electroencefalograma, no tiene utilidad para fines de diagnóstico etiológico (109).
Es necesario destacar que existen una plétora de estudios donde se analiza sobre el costo/efectividad superior del CMA y de la secuenciación masiva para determinar la etiología de la DI, a pesar del coste elevado, en comparación a pruebas de rutina como la RMN, electroencefalograma o el propio cariotipo $(98,113-118)$.

Es importante indicar que siendo la inteligencia y la discapacidad intelectual un rasgo continuo poligénico, se debería realizar una medición del CI en los padres y hermanos del paciente con discapacidad intelectual, con la finalidad de establecer los rangos del CI familiar, principalmente en aquellos niñosadolescentes que tienen un rendimiento escolar bajo pero que no necesariamente presentan un CI menor a 70, y a que a pesar de estar dentro de los rangos usuales, podría tener una condición genética, que eventualmente incluso podría ser de novo y heredado a su descendencia (gráfico 4). Por lo tanto, se podría utilizar la siguiente fórmula $\left(\mathrm{CI}_{\mathrm{p}}+\mathrm{CI}_{\mathrm{m}}\right) / 2 \pm 30$, (donde $C_{p}=$ Coeficiente intelectual 
paterno y $\mathrm{CI}_{m}=$ Coeficiente intelectual materno). Lo anterior expuesto está basado en que los rasgos poligénicos familiares, son generalmente parecidos; y además se ha observado que en pacientes con DI leve, los hermanos suelen tener un CI por debajo de la curva normal, en comparación con aquellos con los pacientes con DI severa (119).

\section{Manejo integral de la discapacidad intelectual}

La heterogeneidad etiológica y clínica de la DI requiere por lo tanto consideraciones individualizadas; sin embargo, se puede tener un marco general para el manejo de los pacientes con DI, teniendo las siguientes consideraciones: i) tratamiento de complicaciones médicas; ii) atención médica preventiva general; iii) tratamiento de condiciones médicas y de otras comorbilidades neurológicas; iv) tratamiento de comportamientos agresivos; v) servicios de rehabilitación; vi) soporte educativo; vii) formación profesional; viii) apoyo social; ix) apoyo a la vida comunitaria; $x$ ) soporte para el nivel apropiado de empleo; xi) transición de servicios pediátricos a adultos; xii) tutela, consideraciones financieras y legales. El modelo óptimo de atención para personas con discapacidad intelectual es un modelo de atención interdisciplinaria en el marco de un servicio clínico o centro médico. El profesional médico de atención primaria debe brindar atención médica preventiva y general, además de facilitar y coordinar la atención consultiva especializada y el acceso a los servicios de apoyo necesarios (27).

Se están creando las estrategias necesarias para el descubrimiento de nuevas drogas, utilizando la reprogramación de las células madre y edición génica, con la finalidad de realizar una medicina personalizada $(42,120)$.

\section{CONCLUSIONES}

La capacidad de determinar la etiología de la discapacidad intelectual es un reto constante para el especialista. La correcta determinación de la etiología resulta del criterio, experiencia y el seguimiento de las guías clínicas. La pericia clínica y el uso prudente de los recursos diagnósticos es vital en regiones con recursos limitaciones como Perú y varios otros latinoamericanos. La determinación de la etiología de la discapacidad intelectual permitirá el adecuado asesoramiento genético, conocer el pronóstico y el planteamiento de alternativas terapéuticas más específicas. Actualmente, se puede determinar la determinar la etiología de DI hasta en un $90 \%$ de los casos utilizando las nuevas tecnologías ómicas, como el análisis cromosómico por micromatrices y la secuenciación masiva.

Agradecimientos: A los Doctores Anahí Venero y Jorge La Serna por su valoración en la sintaxis de la revisión.

\section{Correspondencia:}

Hugo Hernán Abarca Barriga, Servicio de Genética \& EIM, Instituto Nacional de Salud del Niño,

Av. Brasil 600, Breña, Lima, Perú.

Correo electrónico: habarca@insn.gob.pe / hernanabar@yahoo.es,

Teléfono: 51979301132

Conflicto de intereses: Ninguno

\section{REFERENCIAS BIBLIOGRÁFICAS}

1. Real Academia Española. Inteligencia. Madrid: Real Academia Española; 2019. (Citado el 30 de marzo de 2020) Disponible en: http://lema.rae.es/drae2001/ srv/search?id=2qlbggjrBDXX2HVuWUL7

2. Sternberg RJ. Intelligence. Dialogues Clin Neurosci. 2012;14(1):19-27.

3. Plomin R, von Stumm S. The new genetics of intelligence. Nat Rev Genet. 2018;19(3):148-59.

4. Goriounova NA, Mansvelder HD. Genes, cells and brain areas of intelligence. Front Hum Neurosci. 2019; 13:0-0. (Citado el 30 de marzo de 2020) Disponible en: https://www.frontiersin.org/ articles/10.3389/fnhum.2019.00044/full

5. Deary IJ, Harris SE, Hill WD. What genome-wide association studies reveal about the association between intelligence and physical health, illness, and mortality. Curr Opin Psychol. 2019; 27:6-12.

6. Wechsler D. The measurement and appraisal of adult intelligence. Filadelfia: The Williams \& Wilkins Company; 1958.

7. Sternberg R. Encyclopedia of human intelligence. Wisconsin: Macmillan Library; 1994.

8. Wechsler D. WAIS-IV Administration and scoring manual (Wechsler Adult Intelligence Scale). Pearson; 2008.

9. Wrigth J. International Encyclopedia of the Social \& Behavioral Sciences. 2nd ed. Elsevier; 2015.

10. Lynn R, Vanhanen T. IQ and the Wealth of Nations. 
Washington: Summit Publishers; 2002.

11. Lynn R, Meisenberg G, Mikk J, Williams A. National IQs predict differences in scholastic achievement in 67 countries. J Biosoc Sci. 2007;39(6):861-74.

12. Duncan J, Seitz RJ, Kolodny J, Bor D, Herzog H, AhmedA, et al. Aneural basis for general intelligence. Science. 2000;289(5478):457-60.

13. Haier RJ, Jung RE. Beautiful minds (i.e., brains) and the neural basis of intelligence. Behav Brain Sci. 2007;30(2):174-8.

14. Coleman JRI, Bryois J, Gaspar HA, Jansen PR, Savage JE, Skene N, et al. Biological annotation of genetic loci associated with intelligence in a meta-analysis of 87740 individuals. Mol Psychiatry. 2019;24(2):18297.

15. Hill WD, Marioni RE, Maghzian O, Ritchie SJ, Hagenaars SP, McIntosh AM, et al. A combined analysis of genetically correlated traits identifies 187 loci and a role for neurogenesis and myelination in intelligence. Mol Psychiatry. 2019;24(2):169-81.

16. Zechner U, Wilda M, Kehrer-Sawatzki H, Vogel W, Fundele R, Hameister H. A high density of $\mathrm{X}$-linked genes for general cognitive ability: a runaway process shaping human evolution? Trends Genet. 2001;17(12):697-701.

17. Skuse DH. X-linked genes and mental functioning. Hum Mol Genet. 2005;14 (S1):27-32.

18. Bouchard TJ, McGue M. Genetic and environmental influences on human psychological differences. J Neurobiol. 2003; 54(1):4-45.

19. PanizzonMS, VuoksimaaE,SpoonKM,JacobsonKC, Lyons MJ, FranzCE, etal. Genetic andEnvironmental Influences of General Cognitive Ability: Is g a valid latent construct? Intelligence. 2014;43: 65-76.

20. Sauce B, Matzel LD. The paradox of intelligence: Heritability and malleability coexist in hidden geneenvironmentinterplay.PsycholBull.2018;144(1):2647.

21. Chen Y, Chen C, Wu T, Qiu B, Zhang W, Fan J. Accessing the development and heritability of the capacity of cognitive control. Neuropsychologia. 2020;139: 107361.

22. Boat TF, Wu JT, Disorders $\mathrm{C}$ to $\mathrm{E}$ the SSIDP for $\mathrm{C}$ with $\mathrm{M}$, Populations $\mathrm{B}$ on the $\mathrm{H}$ of $\mathrm{S}$, Board on ChildrenY,MedicineIof,etal.ClinicalCharacteristics of Intellectual Disabilities. En: Mental Disorders and Disabilities Among Low-Income Children. Washington DC: National Academies Press (US); 2015 (Citado el 30 de marzo de 2020) Disponible en: https://www.ncbi.nlm.nih.gov/books/NBK332877/

23. Brown KA, Parikh S, Patel DR. Understanding basic concepts of developmental diagnosis in children. Transl Pediatr. 2020;9(Suppl 1):S9-22.

24. Association AP. Diagnostic and Statistical Manual of Mental Disorders (DSM-5®). American Psychiatric Pub; 2013.
25. Kaufman L, Ayub M, Vincent JB. The genetic basis of non-syndromic intellectual disability: a review. J Neurodev Disord. 2010;2(4):182-209.

26. Gardner M, Amor D. Gardner and Sutherland's Chromosome abnormalities and genetic counseling. Oxford: Oxford University Press; 2018.

27. Patel D, Cabral MD, Ho A, Merrick J. A clinical primer on intellectual disability. Translational Pediatrics. 2020;9(1):23-5.

28. Katz G, Lazcano-Ponce E. Intellectual disability: definition, etiological factors, classification, diagnosis, treatment and prognosis. Salud Pública México. 2008;50:132-41.

29. Maulik PK, Darmstadt GL. Childhood disability in low- and middle-income countries: Overview of screening, prevention, services, legislation, and epidemiology. Pediatrics. 2007;120 (Supplement 1):S1-55.

30. Mercadante MT, Evans-Lacko S, Paula CS. Perspectives of intellectual disability in Latin American countries: epidemiology, policy, and services for children and adults. Curr Opin Psychiatry. 2009;22(5):469-74.

31. Ropers HH. Genetics of early onset cognitive impairment. Annu Rev Genomics Hum Genet. 2010;11:161-87.

32. Klein E, Gallardo B, Chávez M1, Abarca-Barriga H. Atlas de dismorfología pediátrica. Lima: Fondo Editorial del INSN; 2012.

33. Bejerot S, Nordin V. Autism spectrum syndrome replaces Asperger syndrome and autism. Lakartidningen. 2014;111(39):1660-3.

34. Sharma SR, Gonda X, Tarazi FI. Autism Spectrum Disorder: Classification, diagnosis and therapy. Pharmacol Ther. 2018;190:91-104.

35. Shulman C, Esler A, Morrier MJ, Rice CE. Diagnosis of autism spectrum disorder across the lifespan. Child Adolesc Psychiatr Clin N Am. 2020;29(2):253-73.

36. Le Hellard S, Steen VM. Genetic architecture of cognitive traits. Scand J Psychol. 2014;55(3):255-

62.

37. Willemsen MH, Kleefstra T. Genetic diagnostics in intellectual disability: what is the benefit? Ned Tijdschr Geneeskd. 2014;158:A8098.

38. MalinowskiJ,MillerDT,DemmerL, GannonJ,Pereira EM, Schroeder MC, et al. Systematic evidence-based review: outcomesfromexomeand genomesequencing for pediatric patients with congenital anomalies or intellectual disability. Genet Med. 2020;22(6):9861004.

39. Haraksingh RR, Snyder MP. Impacts of variation in the human genome on gene regulation. J Mol Biol. 2013;425(21):3970-7.

40. Lee S, Rudd S, Gratten J, Visscher PM, Prins JB, Dawson PA. Gene networks associated with nonsyndromic intellectual disability. J Neurogenet. 2018; 
Avances genómicos de la última década y su influencia en el enfoque diagnóstico de la discapacidad intelectual.

32(1):6-14.

41. Sathyanesan A, Zhou J, Scafidi J, Heck DH, Sillitoe RV, Gallo V. Emerging connections between cerebellar development, behavior and complex brain disorders. Nat Rev Neurosci. 2019;20(5):298-313.

42. Tărlungeanu DC, Novarino G. Genomics in neurodevelopmental disorders: an avenue to personalized medicine. Exp Mol Med. 2018;50(8): 100. doi: 10.1038/s12276-018-0129-7

43. Vissers LELM, Gilissen C, Veltman JA. Genetic studies in intellectual disability and related disorders. Nat Rev Genet. 2016;17(1):9-18.

44. Kochinke K, Zweier C, Nijhof B, Fenckova M, Cizek P, Honti F, et al. Systematic phenomics analysis deconvolutes genes mutated in intellectual disability into biologically coherent modules. Am J Hum Genet. 2016;98(1):149-64.

45. Jamra R. Genetics of autosomal recessive intellectual disability. Med Genet. 2018;30(3):323-7.

46. AbarcaBarrigaH,TrubnykovaM,ChávezM,LaSerna $\mathrm{J}$, Poterico JA. Factores de riesgo en las enfermedades genéticas. Acta Médica Peruana. 2018;35(1):43-50.

47. Lynch M. Rate, molecular spectrum, and consequences of human mutation. Proc Natl Acad Sci U S A. 2010;107(3):961-8.

48. Abarca H, Campoverde G, Taquia E, Herrera H. Hallazgos citogenéticos de abortos en el Servicio de Citopatologíay Citogenética del Hospital Nacional Guillermo Almenara Irigoyen- 1998-junio 2006. Revista del Cuerpo Médico. 2005; 1:0-0.

49. Guio H, Poterico JA, Levano KS, Cornejo-Olivas M, Mazzetti P, Manassero-Morales G, et al. Genetics and genomics in Peru: Clinical and research perspective. Mol Genet Genomic Med. 2018;6(6):873-86.

50. Vacca RA, Bawari S, Valenti D, Tewari D, Nabavi SF, ShirooieS, etal.Downsyndrome:Neurobiological alterationsand therapeutictargets. NeurosciBiobehav Rev. 2019;98:234-55.

51. Zhang F, Gu W, Hurles ME, Lupski JR. Copy number variation in human health, disease, and evolution. Annu Rev Genomics Hum Genet. 2009;10:451-81.

52. Goldenberg P. An Update on common chromosome microdeletion and microduplication syndromes. Pediatr Ann. 2018;47(5):e198-203.

53. Grati FR, Molina Gomes D, Ferreira JCPB, Dupont C, Alesi V, Gouas L, et al. Prevalence of recurrent pathogenic microdeletions and microduplications in over 9500 pregnancies. Prenat Diagn. 2015; 35(8):801-9.

54. Wang R, Lei T, Fu F, Li R, Jing X, Yang X, et al. Application of chromosome microarray analysis in patients with unexplained developmental delay/ intellectual disability in South China. Pediatr Neonatol. 2019;60(1):35-42.

55. Almal SH, Padh H. Implications of gene copynumber variation in health and diseases. $\mathrm{J}$ Hum
Genet. 2012;57(1):6-13.

56. Lohan S, Spielmann M, Doelken SC, Flöttmann R, Muhammad F, Baig SM, et al. Microduplications encompassing the Sonic hedgehog limb enhancer ZRSareassociatedwithHaas-typepolysyndactylyand Laurin-Sandrow syndrome. Clin Genet. 2014;86(4):318-25.

57. Flöttmann R, Kragesteen BK, Geuer S, Socha M, Allou L, Sowińska-Seidler A, et al. Noncoding copynumbervariations are associated with congenital limb malformation. Genet Med Off J Am Coll Med Genet. 2018;20(6):599-607.

58. Rooms L, Reyniers E, Kooy RF. Subtelomeric rearrangementsinthementallyretarded:acomparison of detection methods. Hum Mutat. 2005;25(6):51324.

59. Chiurazzi P, Pirozzi F. Advances in understanding - genetic basis of intellectual disability. F1000 Res. 2016;5:599-615.

60. Cummings JA, Clemens LG, Nunez AA. Mother counts: how effects of environmental contaminants on maternal care could affect the offspring and future generations. Front Neuroendocrinol. 2010;31(4): 440-51.

61. Govorko D, Bekdash RA, Zhang C, Sarkar DK. Male germline transmits fetal alcohol adverse effect on hypothalamic proopiomelanocortin gene across generations. Biol Psychiatry. 2012;72(5):378-88.

62. Roozen S, Peters G-JY, Kok G, Townend D, Nijhuis J, Curfs L. Worldwide Prevalence of Fetal Alcohol Spectrum Disorders: A Systematic Literature Review Including Meta-Analysis. Alcohol Clin Exp Res. 2016;40(1):18-32.

63. Lange S, Probst C, Gmel G, Rehm J, Burd L, Popova S. Global prevalence of fetal alcohol spectrum disorder among children and youth: A systematic review and meta-analysis. JAMA Pediatr. 2017;171(10):948-56.

64. Messina MP, D’Angelo A, Battagliese G, Coriale G, Tarani L, Pichini S, et al. Fetal alcohol spectrum disorders awareness in health professionals: implications for psychiatry. Riv Psichiatr. 2020;55(2):79-89.

65. Burrowes SG, Salem NA, Tseng AM, Balaraman S, Pinson MR, Garcia C, et al. The BAF (BRG1/ BRM-Associated Factor) Chromatin-Remodeling Complex Exhibits Ethanol Sensitivity in Fetal Neural Progenitor Cells and Regulates Transcription at the Mir-9-2 Encoding Gene Locus. Alcohol Fayettev N. 2017; 60:149-58.

66. Adams J. Similarities in genetic mental retardation andneuroteratogenicsyndromes. PharmacolBiochem Behav. 1996;55(4):683-90.

67. Suuberg A. Psychiatric and Developmental Effects of Isotretinoin (Retinoid) Treatment for Acne Vulgaris. Curr Ther Res Clin Exp. 2019; 90:27-31. 
68. Liu Q, Van Bortle K, Zhang Y, Zhao M-T, Zhang JZ, GellerBS, etal.Disruption ofmesoderm formation during cardiac differentiation due to developmental exposure to 13-cis-retinoic acid. Sci Rep. 2018;8:12960. doi: 10.1038/s41598-018-31192-0

69. Vendramini-Pittoli S, Guion-Almeida ML, RichieriCosta A, Santos JM, Kokitsu-Nakata NM. Clinical findings in children with congenital anomalies and misoprostol intrauterine exposure: a study of 38 cases. J Pediatr Genet. 2013;2(4):173-80.

70. Vauzelle C, Beghin D, Cournot M-P, Elefant E. Birth defects after exposure to misoprostol in the first trimester of pregnancy: prospective follow-up study. Reprod Toxicol Elmsford N. 2013; 36:98-103.

71. Murphy ME, Westmark CJ. Folic Acid Fortification and Neural Tube Defect Risk: Analysis of the Food Fortification Initiative Dataset. Nutrients.

2020;12(1).

72. Ostrander B, Bale JF. Congenital and perinatal infections. Handb Clin Neurol. 2019;162:133-53.

73. al-Haddad BJS, Oler E, Armistead B, Elsayed NA, Weinberger DR, Bernier R, et al. The fetal origins of mental illness. Am J Obstet Gynecol. 2019;221(6):549-62.

74. Huang J, Zhu T, Qu Y, Mu D. Prenatal, Perinatal andNeonatalRiskFactorsforIntellectualDisability:A Systemic Review and Meta-Analysis. PLoS ONE. 2016; 11(4): e0153655. doi: 10.1371/journal. pone. 0153655

75. Fan Y-S, Ouyang X, Peng J, Sacharow S, Tekin M, Barbouth D, et al. Frequent detection of parental consanguinity in children with developmental disorders by a combined CGH and SNP microarray. Mol Cytogenet. 2013;6(1):38-43.

76. Wadhawan I, Hai Y, Foyouzi Yousefi N, Guo X, Graham JM, Rosenfeld JA. De novo copy number variants and parental age: Is there an association? Eur J Med Genet. 2019;103829.

77. KongA, FriggeML, Masson G, Besenbacher S, Sulem $\mathrm{P}$, Magnusson $\mathrm{G}$, et al. Rate of de novo mutations, father's age, and disease risk. Nature. 2012;488(7412):471-5.

78. Silverman W. Prevention of intellectual and developmental disabilities. Intellect Dev Disabil. 2009; 47(4):320-2.

79. Calderón-González R, Calderón-Sepúlveda RF. Prevention of mental retardation. Rev Neurol. 2003;36(2):184-94.

80. Eiris-Puñal J. Aportación de la genética y de los estudios neurometabólicos al diagnóstico del retraso mental:Neurología.com. Rev Neurol. 2006;43:S177180.

81. Clinical utility of genetic and genomic services: a positionstatementoftheAmericanCollege ofMedical GeneticsandGenomics. GenetMed.2015;17(6):5057.
82. Moeschler JB, Shevell M, American Academy of Pediatrics Committee on Genetics. Clinical genetic evaluation of the child with mental retardation or developmentaldelays.Pediatrics.2006;117(6):2304 16.

83. Moeschler JB, Shevell M, Genetics CO. Comprehensive Evaluation of the Child With Intellectual Disability or Global Developmental Delays. Pediatrics. 2014;134(3):e903-18.

84. OMIM. Online Mendelian Inheritance in Man. Baltimore: Escuela de Medicina de la Universidad Johns Hopkins; 2020. (Citado el 30 de marzo de 2020) Disponible en: http://www.omim.org/

85. Library London Medical Database (LMD). The Genetics Resource. Londres: Face2Gene; 2015. (Citado el 11 de octubre del 2017) Disponible en: http://suite.face2gene.com/lmd-library-londonmedical-database-dysmorphology/

86. Robinson PN, Köhler S, Bauer S, Seelow D, Horn D, Mundlos S. The Human Phenotype Ontology: A Tool for Annotating and Analyzing Human Hereditary Disease. Am J Hum Genet. 2008;83(5):610-5.

87. Oti M, Huynen MA, Brunner HG. The biological coherence of human phenome databases. Am J Hum Genet. 2009;85(6):801-8.

88. Dragusin R, Petcu P, Lioma C, Larsen B, Jørgensen HL, Cox IJ, et al. FindZebra: a search engine for rare diseases. Int J Med Inf. 2013;82(6):528-38.

89. Wadhwa RR, Park DY, Natowicz MR. The accuracy of computer-based diagnostic tools for the identification of concurrent genetic disorders. Am J Med Genet A. 2018;176(12):2704-9.

90. Mishima H, Suzuki H, Doi M, Miyazaki M, Watanabe S, Matsumoto T, et al. Evaluation of Face2Gene using facial images of patients with congenital dysmorphic syndromes recruited in Japan. J Hum Genet. 2019;64(8):789-94.

91. Köhler S, Øien NC, Buske OJ, Groza T, Jacobsen JOB, McNamara C, et al. Encoding clinical data with the human phenotypeontology forcomputational differential diagnostics. Curr Protoc Hum Genet. 2019;103(1): e92.

92. Myers L, Anderlid B-M, Nordgren A, Lundin K, Kuja-Halkola R, Tammimies K, et al. Clinical versus automated assessments of morphological variants in twinswithandwithoutneurodevelopmentaldisorders. Am J Med Genet A. 2020;186(5): 1177-1189.

93. Strømme P, Mangelsdorf ME, Scheffer IE, Gécz J. Infantile spasms, dystonia, and other X-linked phenotypes caused by mutations in Aristaless related homeobox gene, ARX. Brain Dev. 2002;24(5):266-

8.

94. Villard L. MECP2 mutations in males. J Med Genet. 2007;44(7):417-23.

95. Thurm A, Himelstein D, D'Souza P, Rennert O, Jiang S, Olatunji D, et al. Creatine Transporter Deficiency: 
Avances genómicos de la última década y su influencia en el enfoque diagnóstico de la discapacidad intelectual.

Screening of Males with Neurodevelopmental Disorders and Neurocognitive Characterization of a Case. J Dev Behav Pediatr JDBP. 2016;37(4):3226.

96. Calleja-Pérez B, Fernández-Perrone AL, FernándezMayoralas DM, Jiménez de Domingo A, Tirado P, López-Arribas S, et al. Genetic studies and neurodevelopment. From effectiveness to genetic models. Medicina (Mex). 2020;80 (Suppl 2):26-30.

97. Shaffer LG, Bejjani BA. A cytogeneticist's perspective on genomic microarrays. Hum Reprod Update. 2004;10(3):221-6.

98. Monroe GR, Frederix GW, Savelberg SMC, de Vries TI, Duran KJ, van der Smagt JJ, et al. Effectiveness of whole-exome sequencing and costs of the traditional diagnostic trajectory in children with intellectual disability. Genet Med Off J Am Coll Med Genet. 2016;18(9):949-56.

99. Srivastava S, Love-Nichols JA, Dies KA, Ledbetter DH, Martin CL, Chung WK, et al. Meta-analysis and multidisciplinary consensus statement: exome sequencing is a first-tier clinical diagnostic test for individualswithneurodevelopmentaldisorders. Genet Med Off J Am Coll Med Genet. 2019;21(11):241321.

100. Stark Z, Tan TY, Chong B, Brett GR, Yap P, Walsh $\mathrm{M}$, et al. A prospective evaluation of whole-exome sequencing as a first-tier molecular test in infants with suspected monogenic disorders. Genet Med Off J Am Coll Med Genet. 2016;18(11):1090-6.

101. Marzancola MG, Sedighi A, Li P. DNA MicroarrayBased Diagnostics. Methods Mol Biol Clifton NJ. 2016;1368:161-178.

102. Miller DT, Adam MP, Aradhya S, Biesecker LG, Brothman AR, Carter NP, et al. Consensus Statement: Chromosomal Microarray Is a First-Tier Clinical Diagnostic Test for Individuals with Developmental Disabilities or Congenital Anomalies. Am J Hum Genet. 2010;86(5):749-764.

103. Battaglia A, Doccini V, Bernardini L, Novelli A, Loddo S, Capalbo A, et al. Confirmation of chromosomal microarray as a first-tier clinical diagnostic test for individuals with developmental delay, intellectual disability, autism spectrum disorders and dysmorphic features. Eur J Paediatr Neurol EJPN Off J Eur Paediatr Neurol Soc. 2013;17(6):589-99.

104. Pratte-Santos R, Ribeiro KH, Santos TA, Cintra TS. Analysis of chromosomal abnormalities by CGHarray in patients with dysmorphic and intellectual disability with normal karyotype. Einstein. 2016;14(1):30-4.

105. Abarca-Barriga HH, Chávez Pastor MA, Trubnykova M, Vásquez F, Poterico JA. Chromosomal microarray analysis in peruvian children with delayed psychomotor development or intellectual disability. Rev Peru Med Exp Salud Publica. 2017;34(3):572-4.

106. Han JY, Jang W, Park J, Kim M, Kim Y, Lee IG. Diagnostic approach with genetic tests for global developmental delay and/or intellectual disability: Single tertiary center experience. Ann Hum Genet. 2019;83(3):115-23.

107. Sotomayor FV, Abarca-Barriga HH. Homozygous Deletion of the CFTR Gene Caused by Interstitial Maternal Isodisomy in a Peruvian Child with Cystic Fibrosis. J Pediatr Genet. 2019;8(3):147-152. DOI:10.1055/s-0039-1678682

108. Ciaccio C, Fontana L, Milani D, Tabano S, Miozzo $\mathrm{M}$, Esposito $\mathrm{S}$. Fragile $\mathrm{X}$ syndrome: a review of clinical and molecular diagnoses. Ital J Pediatr. 2017;43(1):39.

109. van Karnebeek CDM, Jansweijer MCE, Leenders AGE, Offringa M, Hennekam RCM. Diagnostic investigations in individuals with mental retardation: a systematic literature review of their usefulness. Eur J Hum Genet EJHG. 2005;13(1):6-25.

110. Bonilla R, Salazar D, Tanpaiboon P. Laboratory diagnostic approaches in metabolic disorders. Ann Transl Med. 2018; 6(24): 470. doi: 10.21037/ atm.2018.11.05

111. van Karnebeek CDM, Stockler S. Treatable inborn errors of metabolism causing intellectual disability: a systematic literature review. Mol Genet Metab. 2012;105(3):368-81.

112. van Karnebeek CDM, Houben RFA, Lafek M, Giannasi W, Stockler S. The treatable intellectual disability APP www.treatable-id.org: a digital tool to enhance diagnosis \& care for rare diseases. Orphanet J Rare Dis. 2012;7:47.

113. WHO | Cost-effectiveness analysis for health interventions. Washington DC: WHO. (Citado el 7 de agosto de 2020) Disponible en: http://www. who.int/heli/economics/costeffanalysis/en/

114. Tan TY, Dillon OJ, Stark Z, Schofield D, Alam $\mathrm{K}$, Shrestha R, et al. Diagnostic impact and costeffectiveness of whole-exome sequencing for ambulant children with suspected monogenic conditions. JAMA Pediatr. 2017;171(9):855-62.

115. Sagoo GS, Mohammed S, Barton G, Norbury G, Ahn JW, Ogilvie CM, et al. Cost Effectiveness of using Array-CGH for $\mathrm{D}=$ diagnosing learning disability. Appl Health Econ Health Policy. 2015;13(4):421-32.

116. Vrijenhoek T, Middelburg EM, Monroe GR, van Gassen KLI, Geenen JW, Hövels AM, et al. Whole-exome sequencing in intellectual disability; cost before and after a diagnosis. Eur J Hum Genet EJHG. 2018;26(11):1566-71.

117. Córdoba M, Rodriguez-Quiroga SA, Vega PA, Salinas V, Perez-Maturo J, Amartino H, et al. Whole exome sequencing in neurogenetic odysseys: 
An effective, cost- and time-saving diagnostic approach. PloS One. 2018;13(2):e0191228.

118. Hu X, Li N, Xu Y, Li G, Yu T, Yao R-E, et al. Proband-only medical exome sequencing as a costeffective first-tier genetic diagnostic test for patients without prior molecular tests and clinical diagnosis in a developing country: the China experience. Genet Med Off J Am Coll Med Genet. 2018;20(9):1045-53.

119. Reichenberg A, Cederlöf M, McMillan A, Trzaskowski M, Kapra O, Fruchter E, et al.
Discontinuity in the genetic and environmental causes of the intellectual disability spectrum. Proc Natl Acad Sci U S A. 2016;113(4):1098-103.

120. Hettige NC, Manzano-Vargas K, Jefri M, Ernst C. Strategies to Advance Drug Discovery in Rare Monogenic Intellectual Disability Syndromes. Int J Neuropsychopharmacol. 2018;21(3):201-6.

Recibido: 20/07/2020

Aceptado: 11/03/2021 